\title{
Follow-up study on population structure and breeding pattern of the mangrove horseshoe crab Carcinoscorpius rotundicauda in Singapore
}

\author{
Lesley Cartwright-Taylor*, Chia Chi Hsu \\ Nature Society of Singapore (NSS), 510 Geylang Road, \#02-05 The Sunflower, Singapore 389466
}

\begin{abstract}
In 2009 Cartwright-Taylor et al. (2009; Aquat Biol 8:61-69) published a paper showing the monthly changes in population structure and breeding pattern of the mangrove horseshoe crab Carcinoscorpius rotundicauda over a $1 \mathrm{yr}$ period at the Mandai mud-flats at Kranji in Singapore. Although breeding is thought to be year-round, our work demonstrated that the proportion of juveniles in different size groups varied each month, with recruitment into the smallest size classes from November to March with a corresponding decrease in the proportion of adults, and into larger size classes from March to July coupled with an increasing proportion of adults, suggesting periods of high and low breeding activity through the year. Follow-up data, collected for a further $3 \mathrm{yr}$ to determine if this pattern was maintained, indicate that this indeed is a feature of the population. Each January a high proportion of the small juveniles was found consistently in the population, while each July the population was dominated consistently by adults with some large juveniles. Mean incremental growth rate at ecdysis (36\%) from a further 10 ind. confirmed growth rate findings in the first year. The male:female ratios also confirmed findings from the first year with little change from 1 in the sex ratios for the 3 follow-up yr, suggesting mating activity is not strongly seasonal, as occurs in temperate climates. Pairs in amplexus were seen year-round, but the numbers varied from month to month with no apparent seasonal pattern.
\end{abstract}

KEY WORDS: Mangrove horseshoe crabs · Carcinoscorpius rotundicauda - Breeding patterns · Population structure $\cdot$ Growth $\cdot$ Sex ratio

\section{INTRODUCTION}

An understanding of the biology and behaviour of a species is important in developing strategies for its conservation. Horseshoe crabs are assuming an everincreasing importance in biomedical research as the number of applications for compounds from them for medical use constantly increases (Chatterji \& Shaharom 2011). In Asia horseshoe crabs are also harvested for consumption (Tan et al. 2011). None of the Asian species are being bred in captivity on a commercial scale, so animals are still collected from the wild for these purposes. In addition, there is increasing evidence that anthropogenic activities related to coastal development and fishing are respon- sible for shrinking spawning and foraging sites of all the Asian horseshoe crab species (Chen \& Hsieh 2011, Mishra \& Mishra 2011). Adaptive management methods used in the USA for the Atlantic horseshoe crab fisheries could be applicable in Asia for the Asian species in situations where habitat management may be the focus, such as in Singapore, where land use conflicts with habitat protection (Millard \& Smith 2011). However, such methods require knowledge of the breeding patterns and spawning sites of the species.

A 1 yr study (September 2007 to July 2008) on the population structure of the mangrove horseshoe crab Carcinoscorpius rotundicauda (Latreille, 1802), which inhabits the Mandai mudflats of Kranji in the north of 
Singapore (Cartwright-Taylor et al. 2009), indicated that although this species breeds year-round there may be periods of high and low breeding activity. The study demonstrated increasing recruitment into successively smaller juvenile size classes from September until January, when the greatest recruitment into the smallest juvenile size classes was found, and a correspondingly low proportion of adults was observed in the population throughout this period. This increase was followed by increasing recruitment into the larger juvenile sizes and an increase in the proportion of adults as the year progressed until June and July when the population was dominated by adults with very few juveniles. Small juveniles of $2 \mathrm{~cm}$ in carapace width were seen each month, suggesting that some breeding must be taking place year-round. However, data were presented for only $1 \mathrm{yr}$. Using the same methods as before, follow-up data were collected for the next $3 \mathrm{yr}$ to determine if the pattern of monthly changes in the population structure was maintained. Such confirmation is needed so that efforts to manage the site can allow for this change in breeding activity. this period. The percent of adults in amplexus each month are also presented.

\section{RESULTS}

During the follow-up study period 20 site visits were made, during which a total of 6572 ind. were collected. Sample size varied from 60 crabs in June 2009 to 771 in December 2008 with a mean $( \pm$ SD sample size) of $328.6 \pm 178.1$ crabs.

\section{Sex ratios}

The number of crabs captured (Table 1) and the sex ratios (males:females) (Fig. 1) for each month are given below. For consistency with the previous study, juveniles are classified as those $<8 \mathrm{~cm}$ carapace width because this was the smallest size of males observed and the smallest size of males found in amplexus and, therefore, sexually mature.

\section{MATERIALS AND METHODS}

The study site at the Mandai mudflats at Kranji on the north coast of the main island of Singapore was described previously (Cartwright-Taylor et al. 2009). Searches were continued from October 2008 to June 2011 within $3 \mathrm{~d}$ of the full moon spring tide. Search methods, data collection of carapace width and gender, measurement of incremental growth in prosomal width at ecdysis, data entry, training and supervision of volunteers remained the same as used previously (CartwrightTaylor et al. 2009). Searches could not be made every month due to unfavourable tide times. Sex ratios are presented for each month that collections were made over the $3 \mathrm{yr}$ followup period. As before, carapace width data were arranged into classes of $1 \mathrm{~cm}(0$ to $<1,1$ to $<2 \mathrm{~cm}$ etc. $)$, and the percentages of total catch are presented as frequency distributions for each month for which there are 2 or more collections over the $3 \mathrm{yr}$ followup, to demonstrate consistency over
Table 1. Carcinoscorpius rotundicauda. Numbers of mangrove horseshoe crabs of different age and sex classes collected from the Mandai mudflats in the period from October 2008 to October 2011. Juveniles were $<8 \mathrm{~cm}$ in carapace width, while adults were $\geq 8 \mathrm{~cm}$. Sex ratio is the number of males:females

\begin{tabular}{|lrrrrrr|}
\hline $\begin{array}{l}\text { Collection } \\
\text { month }\end{array}$ & $\begin{array}{c}\text { Total } \\
\mathrm{n}\end{array}$ & Juveniles & Adults & Males & Females & Sex ratio \\
\hline $\mathbf{2 0 0 8}$ & & & & & & \\
Oct & 198 & 86 & 112 & 54 & 58 & 0.93 \\
Nov & 375 & 116 & 259 & 139 & 120 & 1.16 \\
Dec & 771 & 588 & 183 & 91 & 92 & 0.99 \\
$\mathbf{2 0 0 9}$ & & & & & & \\
Jan & 456 & 363 & 93 & 47 & 46 & 1.02 \\
Feb & 346 & 308 & 38 & 19 & 19 & 1.00 \\
Mar & 62 & 47 & 15 & 5 & 10 & 0.50 \\
June & 60 & 42 & 18 & 14 & 4 & 3.50 \\
July & 63 & 8 & 55 & 42 & 13 & 3.23 \\
Oct & 186 & 93 & 93 & 50 & 43 & 1.16 \\
$\mathbf{2 0 1 0}$ & & & & & & \\
Jan & 443 & 329 & 114 & 74 & 40 & 1.85 \\
Mar & 246 & 82 & 164 & 93 & 71 & 1.31 \\
May & 273 & 100 & 173 & 101 & 72 & 1.40 \\
July & 488 & 68 & 420 & 234 & 186 & 1.26 \\
Nov & 373 & 120 & 253 & 124 & 129 & 0.96 \\
Dec & 301 & 3 & 298 & 124 & 174 & 0.71 \\
$\mathbf{2 0 1 1}$ & & & & & & \\
Mar & 337 & 202 & 135 & 71 & 64 & 1.11 \\
Apr & 495 & 210 & 285 & 138 & 147 & 0.94 \\
May & 521 & 121 & 400 & 218 & 182 & 1.20 \\
June & 384 & 14 & 370 & 216 & 154 & 1.40 \\
Oct & 194 & 116 & 78 & 34 & 44 & 0.77 \\
Total & 6572 & 3016 & 3556 & 1888 & 1688 & \\
\hline
\end{tabular}




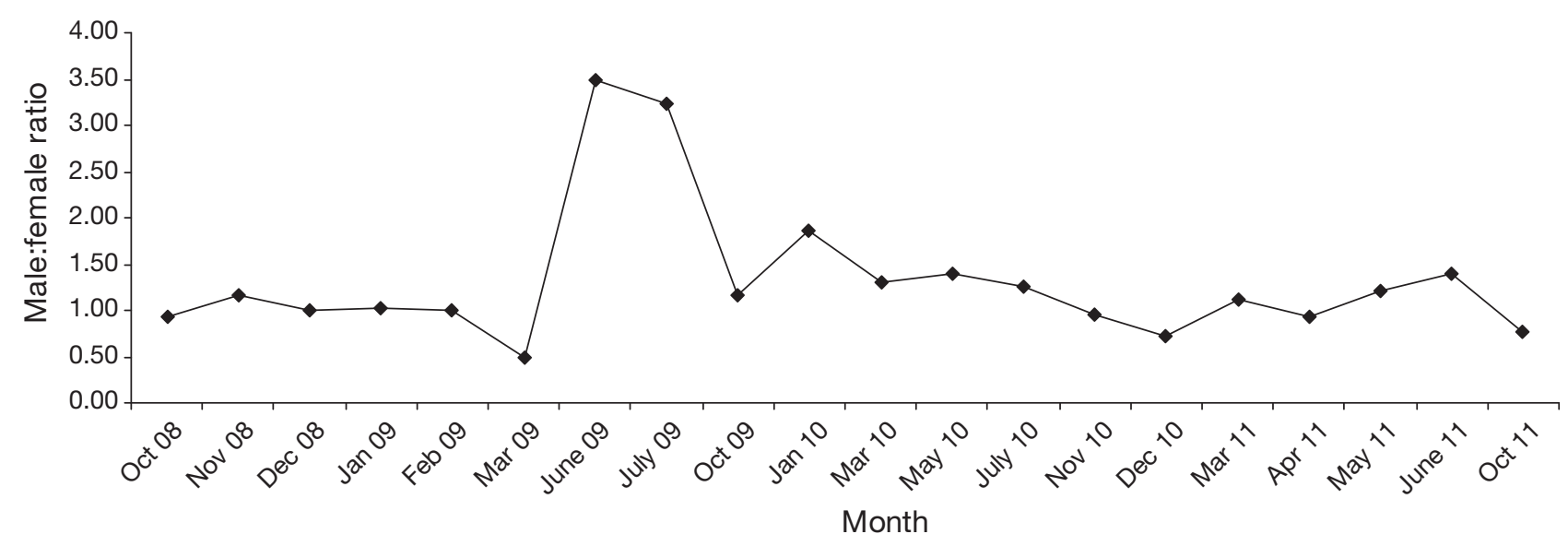

Fig. 1. Carcinoscorpius rotundicauda. Sex ratios (no. of males:females) from Mandai mudflats at Kranji over 3 yr of collections following the initial 2007/2008 study

As in the previous study (Cartwright-Taylor et al. 2009), the male:female ratios showed consistently little change from 1 (Fig. 1), except in March 2009 when it dropped to 0.5 and in June and July 2009 when it rose to 3.5 and 3.23 respectively. However these extremes may have been affected by the low numbers collected at these visits and were not repeated for the same month in other years.

\section{Frequency distributions}

The frequency distributions of the size classes show consistency for the same month in different years for most months (Fig. 2) and with the previously reported year (Cartwright-Taylor et al. 2009). However, March and June 2009 showed the lowest consistency with these months in other years, but this
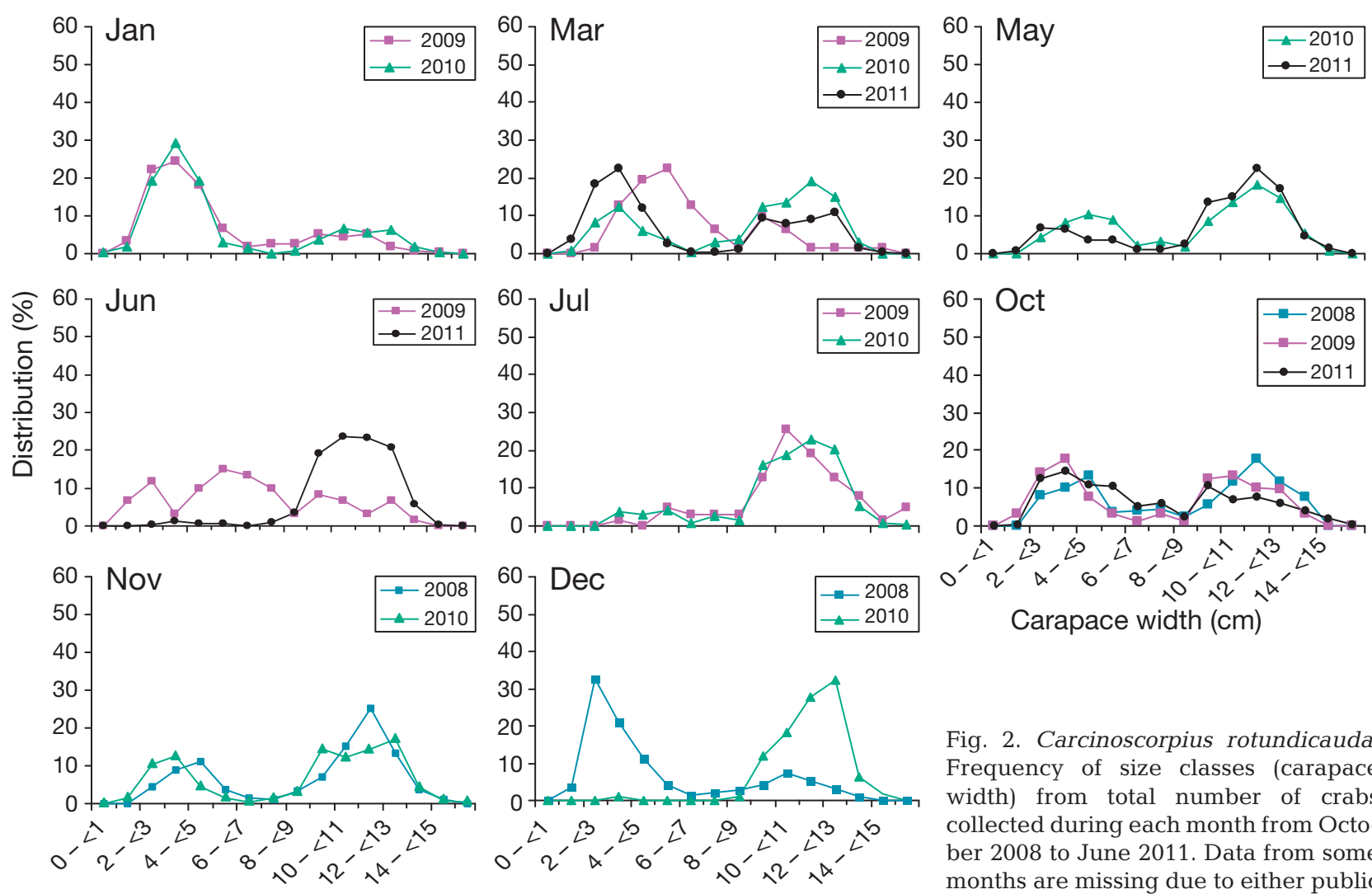

Fig. 2. Carcinoscorpius rotundicauda. Frequency of size classes (carapace width) from total number of crabs collected during each month from October 2008 to June 2011. Data from some months are missing due to either public holidays or unfavourable tide times 
may be due to the low number of individuals collected at these visits, 62 and 60 crabs respectively.

January showed strong consistency between the 2 follow-up yr and with the first year in 2008. Each January consistently showed the highest recruitment into the small size classes ( 2 to $4 \mathrm{~cm}$ ) with few adults represented. As the months progressed through each year the percentage in the small size classes declined with a corresponding increase in the percentage of adults, until in July of each year there were low percentages of all sizes smaller than $9 \mathrm{~cm}$ in the population. In October and November of each year the percentage of small size classes increased again with a commensurate reduction in the percentage of adults in the population. Only December showed an entirely inconsistent pattern between 2008 and 2010 with a high percentage of small sizes in one year and a very low percentage of sizes less than $9 \mathrm{~cm} 2 \mathrm{yr}$ later, in spite of a large sample collected each time. Apart from December, each month showed a consistent pattern with the same month in other years.

During the follow-up study an additional 10 crabs, from 1.5 to $9.1 \mathrm{~cm}$ in carapace width, were seen in the process of ecdysis. The mean incremental growth was $36 \pm 9.8 \%$, which showed little change from the previous report of $33 \%$ from 6 ind.

\section{Breeding activity}

The mean $( \pm \mathrm{SD})$ percentage of individuals in amplexus out of all adults caught was $6.87 \pm 6.88 \%$. However, these numbers are likely to be an underestimate because some pairs or groups came apart before they could be recorded. The percent of individuals in amplexus varied from $0 \%$ in June 2009 when the sample size was small, and again in January 2010 , to $21.5 \%$ in October 2009. Some months showed consistency in the percentage of individuals in amplexus in successive years (10.91 and $10.95 \%$ in July 2009 and 2010 respectively), while other months showed little consistency (10.71 and $21.51 \%$ in October 2008 and 2009 respectively). The mean percentage of individuals in amplexus was lower than that reported for the first year but this may be explained by some collections with very low numbers of adults.

In June 2011 egg nests, which had never been seen before in Singapore, were found by the authors at the extreme high tide level. One was in a narrow strip of coarse substrate among the mangroves, another near the base of the sea wall and a third along the mouth of a nearby freshwater outlet, all sites close enough to the mud flats to account for the high periodic recruitment into the small size classes of the population. Only 3 nest sites were found, and the most eggs found in any nest was 10 at the first observation. This low number may be due to the inexperience of the searchers in looking for eggs and nests, but there were certainly not the thousands of eggs in each cluster as has been reported for Limulus spp. (Weber \& Carter 2009).

\section{DISCUSSION}

The study on the population of mangrove horseshoe crabs on the Mandai mudflats at Kranji in Singapore over 4 yr confirms the early findings on the changes in the population structure observed in the first year (Cartwright-Taylor et al. 2009); although breeding occurs year-round, as shown by finding very small juveniles each month, there are periods of high breeding activity that result in a high percentage of small juveniles in the population. This is the first long-term study of mangrove horseshoe crabs at the site.

The population structure in the same month during consecutive years showed remarkable consistency, with a discernable trend of young juveniles appearing in January, juvenile numbers decreasing towards the middle of the year and then increasing from September onwards to begin the cycle again, confirming periods of high and low breeding activity, but with some activity year-round. The only month that showed an anomalous pattern was December. In 2008 there was recruitment into the small juvenile classes that continued into the following month as expected, but in December 2010 a complete reversal of this pattern was observed. In that month the population was made up almost entirely of adults, yet the previous month showed consistency with November 2 yr earlier, and by March the following year the pattern had returned to normal. There is no apparent explanation for the dearth of juveniles in December 2010, but there may have been a period of very low egg-laying activity in the preceding months or an unusually high mortality of very small juveniles that year. Although the presence of juveniles in each month suggests year-round breeding activity, it is still not clear when the periods of peak breeding activity occur or how long the larval stage is for this population. The only information available on larval development of tropical populations is from captive-bred individuals (Zadeh et al. 2009).

The sex ratios each month showed a very similar pattern to the first year with little change from 1 each 
month except in the 2 mo with very low collection numbers. As in the first year, there were no months when males substantially outnumbered females, which might suggest a period of high breeding activity as has been reported for Limulus polyphemus in temperate climates during the breeding season (Smith et al. 2009). Tachypleus gigas in tropical Malaysia also shows a sex ratio of 1 during most of the year with occasional increases in numbers of males (Tan et al. 2011). In addition the numbers of individuals in amplexus, which had no discernable increase in any particular month each year, also suggest year-round breeding activity but do not give any clues to periods of high breeding activity.

In each collection made during the follow-up period, a very low percentage of sub-adults - individuals with 6 to $9 \mathrm{~cm}$ carapace width - were observed. Studies in China (Hu et al. 2011a) indicate that small Carcinoscorpius rotundicauda juveniles live close to shore while the larger juveniles -7 to $9 \mathrm{~cm}$ in sizelive offshore for feeding. The sub-adults at Kranji likely move from the shore into the deeper waters in the centre of the Strait of Johor.

The mean incremental growth in prosomal width at ecdysis measured in this follow-up study ( $36 \%$ ) was consistent with that during the first year and provides further information on the growth rate of wild mangrove horseshoe crabs. These results were also similar to those reported by Zadeh et al. (2009) for early stage instars bred in captivity (33.6 to $39.5 \%$ ).

The findings in the present study concur with the observed changes in population structure reported from the first year of the study, indicating that this changing pattern in the population through the year is a real, annual phenomenon not just an isolated occurrence and that there are probably periods of high and low breeding activity during the year. However, with no seasons in the tropics, determining what might trigger periods of high breeding activity is difficult. The recent finding of nesting sites of the mangrove horseshoe crabs at Kranji is important because it now confirms that the entire life cycle of this population occurs at the study site. The nest sites can be monitored to provide more information on the life cycle of this population. These sites are also clearly vulnerable because they are in areas at risk of destruction if coastal development in the Kranji area proceeds. Protection of the nesting sites is vital if the population is to survive. Site visits continue each month to observe and quantify the number of nesting sites and eggs within each nest, which will help to link these data with the numbers of juveniles in the population and determine when the periods of high breeding activity occur. This monitoring will also shed light on the full breeding cycle of this population. Such information is important to support proposals for protection of the whole of the mudflats from the highest tide level where the eggs are laid. This population of mangrove horseshoe crabs is the last known breeding population on the main island of Singapore (Cartwright-Taylor et al. 2011), and the habitat of all stages in the life cycle must be protected if it is to survive. Assessing and mapping important and critical horseshoe crab spawning grounds is vital in the conservation of the species, while knowledge of the breeding pattern is important in managing their population size. Reports from southern China indicate that once a horseshoe crab population is extirpated locally, re-establishment takes a long time, even if the habitat is restored (Hu 2011b); any coastal development or land reclamation along the Mandai mudflat will therefore have a devastating effect on this population.

Acknowledgements. We thank the many individual Nature Society members as well as the Singapore school children and their teachers, who gave their time and effort to help with the horseshoe crab searches, and S. Johnson, now in Otago, New Zealand, who helped find the nest sites.

\section{LITERATURE CITED}

Cartwright-Taylor L, Lee J, Hsu CC (2009) Population structure and breeding pattern of the mangrove horseshoe crab Carcinoscorpius rotundicauda in Singapore. Aquat Biol 8:61-69

Cartwright-Taylor L, Yap VB, Hsu CC, Lou ST (2011) Distribution and abundance of horseshoe crabs Tachypleus gigas and Carcinoscorpius rotundicauda around the main island of Singapore. Aquat Biol 13:127-136

Chatterji A, Shaharom F (2011) Present and future of horseshoe crab in biomedical research. Int Workshop Sci Conserv Asian Horseshoe Crabs, Hong Kong, 13 to 16 June 2011

Chen CP, Hsieh HL (2011) The challenges and opportunities for horseshoe crab conservation in Taiwan. Int Workshop Sci Conserv Asian Horseshoe Crabs, Hong Kong, 13 to 16 June 2011

Hu MH, Wang YJ, Cheung SG, Shin PKS, Li QZ (2011a) Relationship of environmental variability and spatial distribution of two horseshoe crab species along nursery beaches of Beibu Gulf Coast, Southern China. Int Workshop Sci Conserv Asian Horseshoe Crabs, Hong Kong, 13 to 16 June 2011

Hu MH, Wang YJ, Cheung SG, Shin PKS, Li QZ (2011b) Distribution, abundance and population structure of horseshoe crabs along three intertidal zones of Beibu Gulf, Southern China. Int Workshop Sci Conserv Asian Horseshoe Crabs, Hong Kong, 13 to 16 June 2011

Millard MJ, Smith DR (2011) Adaptive management of horseshoe crab populations in face of multiple objectives. Int Workshop Sci Conserv Asian Horseshoe Crabs, Hong Kong, 13 to 16 June 2011 
Mishra JK, Mishra A (2011) Anthropogenic effect on the horseshoe crab breeding ground and impact on their population along the North-East Coast of India. Int Workshop Sci Conserv Asian Horseshoe Crabs, Hong Kong, 13 to 16 June 2011

Smith DR, Millard MJ, Carmichael RH (2009) Comparative status and assessment of Limulus polyphemus with emphasis on the New England and Delaware Bay populations. In: Tanacredi JT, Botton ML, Smith DR (eds) Biology and conservation of horseshoe crabs. Springer, New York, NY, p 361-386

Tan AN, Christianus A, Abdul Satar MK (2011) Horseshoe crab Tachypleus gigas (Müller) found at spawning site at Pantai Balok in peninsular Malaysia. Int Workshop Sci

Editorial responsibility: Christine Paetzold, Oldendorf/Luhe, Germany
Conserv Asian Horseshoe Crabs Hong Kong, 13 to 16 June 2011

Weber RG, Carter DB (2009) Distribution and development of Limulus egg clusters on intertidal beaches in Delaware Bay. In: Tanacredi JT, Botton ML, Smith DR (eds) Biology and conservation of horseshoe crabs. Springer, New York, NY, p 249-267

Zadeh SS, Christianus A, Saad CR, Hajeb P, Kamarudin MS (2009) Comparisons in prosomal width and body weight among early instar stages of Malaysian horseshoe crabs, Carcinoscorpius rotundicauda and Tachypleus gigas, in the laboratory. In: Tanacredi JT, Botton ML, Smith DR (eds) Biology and conservation of horseshoe crabs. Springer, New York, NY, p 267-274

Submitted: October 31, 2011; Accepted: November 21, 2011 Proofs received from author(s): January 13, 2012 